\title{
MARCEL MAUSS E NORBERT ELIAS: NOTAS PARA UMA APROXIMAÇÃO EPISTEMOLÓGICA
}

\author{
MARIA DA GRAÇA JACINTHO SETTON*
}

\begin{abstract}
As estruturas da psique humana, as estruturas da sociedade humana e as estruturas da história humana são indissociavelmente complementares, só podendo ser estudadas em conjunto. Elas não existem e se movem na realidade com o grau de isolamento presumido pelas pesquisas atuais. Formam ao lado de outras estruturas, o objeto de uma única ciência humana. (ELIAS, 1994, p. 38)
\end{abstract}

\begin{abstract}
RESUMO: O objetivo deste ensaio é estabelecer algumas relações teóricas entre dois cientistas sociais, Marcel Mauss (1872-1950) e Norbert Elias (18871990). Parte-se do pressuposto que esses autores partilham de alguns princípios epistemológicos semelhantes, princípios estes que são valiosos para a compreensão dos processos educativos e socializadores da atualidade. Relativamente contemporâneos, Mauss e Elias, o primeiro francês, o segundo alemão, ambos judeus, ainda que não sejam devidamente utilizados na área da sociologia da educação, ainda que não tenham sistematizado suas reflexões no campo das teorias da socialização, fornecem insights fundamentais acerca das relações indissociáveis entre indivíduo e estrutura social. É com esse propósito que as próximas considerações serão traçadas.
\end{abstract}

Palavras-chave: Marcel Mauss. Norbert Elias. Fato social total. Configuração. Socialização. Individuação.

\section{Marcel Mauss and Norbert Elias: NOTES ON AN EPISTEMOLOGICAL APPROXIMATIONDICIONÁRIO}

ABSTRACT: The aim of this essay is to establish some theoretical bridges between two social scientists, the French, Marcel Mauss (1872-1950) and the German, Norbert Elias (1887-1990). It starts from the assumption that these authors share some similar epistemological principles, principles that are valuable to the understanding of the education the socialization process today. Contemporaries, Elias and Mauss, both Jews, even not being a reference in the field of sociology of education, and although they have not systematized their thoughts on the field of the theories of socialization,

Professora de Sociologia da Faculdade de Educação da Universidade de São Paulo (USP).

E-mail: gracaset@usp.br 
they provide valuable insights about the inseparable relationship between individual and social structure. It is with this purpose that we will outline the next considerations.

Key words: Marcel Mauss. Norbert Elias. Total social facts. Configuration. Socialization. Individuation.

\section{Marcel Mauss et Norbert Elias: NOTES POUR UNE APPROXIMATION EPISTEMOLOGIQUE}

RÉSUMÉ: L'objectif de cet essai est d'établir quelques relations théoriques entre deux chercheurs des sciences sociales, Marcel Mauss (1872-1950) et Norbert Elias (1887-1990). On part du présupposé que ces auteurs partagent certains principes épistémologiques similaires, lesquels sont précieux pour la compréhension des processus éducatifs et sociabilisants de l'actualité. Relativement contemporains, Mauss et Elias, le premier français, le second allemand, tous deux juifs, bien que n'étant pas dûment utilisés dans l'aire de la sociologie de l'éducation, et bien que n'ayant pas systématisé leurs réflexions dans le champ des théories de la sociabilisation, ils fournissent des insights fondamentaux à propos des relations indissociables entre individu et structure sociale. C'est avec cette approche que les prochaines considérations seront tracées.

Mots-clés: Marcel Mauss. Norbert Elias. Fait social total. Configuration. Socialisation. Individuation.

\section{Introdução}

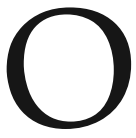

intento de aproximar as contribuições teóricas de Marcel Mauss e Norbert Elias responde à preocupação de ampliar o escopo de investigação teórica da sociologia da educação contemporânea. Embora sejam reconhecidos pelos estudiosos das ciências humanas em geral, é reduzido o número de trabalhos no Brasil que os tem como inspiração. Contudo, algumas incursões acerca dos processos sociais, a partir de uma visão construtivista (CORCUFF, 2001), impõe olhar com maior acuidade as contribuições deixadas por ambos.

Mais ou menos sistematizadas, as reflexões deixadas por eles são testemunhas que, desde o início do século, Mauss e Elias se debruçaram igualmente sobre as maneiras de se conceber os processos pelos quais se constrói a vida em sociedade a partir de uma perspectiva comparativa (MAUSS, 1974c; ELIAS, 1990). Em que pese as diferenças de trajetória profissional, a diversidade temática e o volume da produção de ambos, considera-se que os autores em questão possuem algumas afinidades epistemológicas que muito podem auxiliar no âmbito das investigações dos processos educativos e/ou socializadores da contemporaneidade.

É semelhante também o fato de que nos últimos anos, coincidentemente, Mauss e Elias passaram a ocupar papel de destaque nas produções das ciências humanas. Arriscar-se-ia o palpite de que, nas décadas finais do século passado, uma tendência 
em compreender a construção da realidade social a partir de um ponto de vista mais multidimensional e dialógico torna-se mais presente. Ademais, ainda que o primeiro seja mais reconhecido no campo das investigações antropológicas e o segundo, por sua vez, resgatado, sobretudo, pelos estudos da ciência política e sociologia, é notável o crescimento da importância de ambos nas investigações mais recentes das ciências humanas que dialogam entre si. Assim sendo, dado que a área da Educação é por excelência interdisciplinar, acompanhando os ensinamentos de ambos, consideramos relevante fazer um esforço de superar as fronteiras entre as disciplinas e fazer o melhor uso delas, na tentativa de compreender a complexidade da construção social. ${ }^{1}$

\section{Justificando o problema}

Valeria lembrar que Mauss e Elias são contemporâneos e, em que pese as distintas trajetórias de vida, alguns aspectos nesse quesito se assemelham. Ambos europeus, participaram e sofreram os reveses de duas grandes guerras com a perda de amigos e parentes próximos. Os dois dedicaram a vida à atividade acadêmica com notável empenho, ainda que Mauss tenha iniciado sua carreira de professor mais cedo e com menos dificuldade. Com origem em famílias judias, cultivaram desde cedo uma familiaridade com o universo das letras, desenvolvendo um comprometimento invejável com farta bibliografia engajada de seu tempo. Eruditos e humanistas, empenharam-se de diferentes maneiras nos acontecimentos históricos e políticos da Europa do início do século XX.

Sociólogo e antropólogo francês, nascido em Épinal, França, Marcel Mauss, cuja obra é marcante na sociologia e na antropologia social contemporânea, é considerado, por muitos, como o pai da antropologia do simbólico (CAILLÉ, 1998). Sobrinho de Émile Durkheim, nascido quatorze anos mais tarde e na mesma cidade, estudou com o tio e foi seu assistente, tornando-se professor de religião primitiva (1902) e directeur d'études, na École Pratique des Hautes Études, em Paris. Fundou ainda o Instituto de Etnologia, da Universidade de Paris (1925), e também lecionou no Collège de France (1931-1939). Segundo Fournier (1994), no plano profissional, com 60 anos, na metade dos anos de 1930, foi considerado um sucesso entre seus pares. Ainda que pouco pleiteasse por isso, beneficiou-se de uma audiência sempre significativa. O brilho de Mauss, segundo relatos, foi internacional, praticando uma profícua correspondência com antropólogos e sociólogos do mundo inteiro (OLIVEIRA, 1979; FOURNIER, 1994).

Diferentemente, o sucesso para Elias chegou de maneira muito tardia e a duras penas. Em junho de 1897, nasceu em Breslau, hoje Polônia, Norbert Elias. De família judia e vivendo em uma parte da Alemanha prussiana, Elias teve uma infância burguesa. Filho único e com uma saúde frágil, desde a mais tenra idade foi cercado 
de cuidados parentais. Seria impossível dissociar a trajetória pessoal e a trajetória profissional de Elias. Ambas são interdependentes. Com um percurso de vida desenraizado, fragmentado e por vezes doloroso, Elias passou a maior parte de sua vida tentando conquistar reconhecimento profissional, sublimando de certa forma sentimentos de um outsider. Sua vida profissional foi marcada por muitos percalços. Trabalhou em ritmo contínuo durante a maior parte de sua vida, ainda que seu reconhecimento tenha sido tardio, intermitente e não de todo estabelecido. Sociólogo por opção e não por formação, começou suas leituras na área com 28 anos de idade, em Heidelberg, no círculo social de influência weberiana (ELIAS, 2001; HEINICH, 2001; LEDEL, 2009).

Seria difícil determinar com precisão o momento do século passado em que uma série de reflexões sociológicas se ocupou em fazer um balanço sobre os rumos da sociologia contemporânea. De qualquer modo, seria possível afirmar que os estudos da área, no início do século $X X$, ainda estavam divididos em perspectivas acentuadamente dicotômicas (ANSART, 1990; CORCUFF, 2001). Todavia, Marcel Mauss e Norbert Elias, desde a primeira metade dos novecentos, demonstraram sistematizações significativas de questionamento sobre o poder explicativo de paradigmas centrados nas estruturas ou nas determinações sociais de ordem unicamente material e ou simbólica. Num caminhar vagaroso, mas ao mesmo tempo decisivo, Mauss e Elias parecem ter auxiliado nesta travessia epistemológica, problematizando um tema e um objeto de análise que marcam o campo de investigação da sociologia da educação. Ou seja, trabalharam na direção de incorporar nas análises sociológicas perspectivas mais complexas, em que as relações indissociáveis entre individuo e sociedade e a interpenetração de dimensões simbólicas e materiais se dão de maneira processual e relacional. De maneira assistemática em um (Mauss), porém bastante expressiva em outro (Elias), identifica-se um esforço de suplantar visões rígidas e estáticas da construção dos processos sociais. Seria possível aludir que a consciência sociológica de se viver em um mundo fragmentado e pluralista emergiu lenta, mas simultaneamente, à perda do monopólio das instituições na formação de um conjunto de disposições que modulavam as formas de agir, pensar e ser dos indivíduos no pósguerra. Nesse sentido, sem que formulassem notadamente essa preocupação, ambos são autores que auxiliam na difícil tarefa de superar uma compreensão estreita sobre a construção do social, ou sobre os processos socializadores, e de postular uma visão processual com base na reciprocidade simbólica de indivíduos entre si. Dado os limites desse artigo, nessas reflexões optou-se por enfatizar o caráter multidimensional e interdisciplinar da sociologia de ambos, sobretudo no que se refere aos aspectos relativos aos processos socializadores. ${ }^{2}$

A noção de socialização é aqui definida como um conjunto expressivo de práticas de cultura que tecem e mantêm os laços sociais, uma área de investigação 
que explora as trocas indissociáveis entre indivíduo e sociedade. Na sua dimensão produtora, difusora e reprodutora, a socialização pode enfocar as instituições como matrizes de cultura, pode enfatizar as estratégias de transmissão e, portanto, de transformação dos valores dos grupos sociais, além de explorar as disposições de cultura incorporadas pelos indivíduos ao longo de suas experiências de vida. De certa forma, os processos socializadores podem enfocar as instituições bem como os indivíduos, associando sistematicamente as visões macro e microssociais. Nesse sentido, ela deixa de ser apenas uma noção de integração explicitamente vinculada a uma tradição sociológica para ser vista de modo mais abrangente, como um processo construído coletiva e individualmente e capaz de dar conta das diferentes maneiras de ser e estar no mundo (SETTON, 2009). Como diria Darmon (2006), a socialização não designa um domínio dos fatos, mas é uma maneira de se compreender o real; é um olhar, uma perspectiva analítica que se constrói frente ao fenômeno da realização objetiva e subjetiva do social.

Numa espécie de crítica severa (ELIAS, 1999) ou velada (MAUSS, 1974a) a um sociologismo ou o um holismo, os autores questionam o postulado segundo o qual o indivíduo, sendo produto de estruturas sociais, poderia ser negligenciado. Numa tentativa de superar as versões dicotômicas de compreensão, ou seja, contra o estruturalismo e o individualismo, a sociologia destes autores tenta apreender indivíduos plurais, de acordo com Corcuff (2001), indivíduos produzidos e produtores de relações sociais variadas. Contudo, não se considera que eles fundem uma nova escola, uma nova corrente dotada de homogeneidade. Trata-se mais de um espaço de problemas e de questões epistemológicas que, em uma nova perspectiva, tenderiam a ver as realidades sociais como construções históricas e cotidianas de atores individuais e coletivos.

Mais especificamente, a partir dos conceitos de fato social total e (con)figuração, ${ }^{3}$ respectivamente, Mauss $(1974 a)$ e Elias $(1994,1999)$ permitem a análise da formulação das disposições de cultura individuais e grupais como amálgamas de estruturas históricas, psicológicas e sociológicas anteriores. Ambos concordariam que não são apenas os pertencimentos sociais e a condição material que comandam as disposições dos indivíduos. Em sociedades tradicionais ou em condição de modernidade cultural, o indivíduo estabeleceria articulações com uma multiplicidade de dimensões simbólicas, às vezes distantes ou virtuais, mas com base nas quais os sujeitos forjariam uma identificação pessoal.

\section{O conceito de fato social total e o fenômeno da socialização}

Em Ensaio sobre a dádiva. Forma e razão da troca nas sociedades arcaicas, ${ }^{4}$ Mauss (1974a) analisando o regime de direito contratual e o sistema de prestações 
econômicas de sociedades ainda chamadas "primitivas", apresenta a noção de fato social total. Mauss refere-se a um conjunto enorme de fatos que se relacionam de maneira complexa. Nesses fenômenos

[...] tudo se mistura, tudo o que constitui a vida propriamente social das sociedades que precederam as nossas - até as da proto-história. Nesses fenômenos sociais "totais", como nos propomos chamá-los, exprime-se, ao mesmo tempo e de uma só vez, toda espécie de instituições: religiosas, jurídicas e morais - estas políticas e familiais ao mesmo tempo; econômicas - supondo formas particulares de produção e de consumo, ou antes, de prestação e de distribuição, sem contar os fenômenos estéticos nos quais desembocam tais fatos e os fenômenos morfológicos que manifestam estas instituições. (MAUSS, op. cit., p. 41)

Ao longo desse texto, Mauss passa a relatar as principais características dos fenômenos sociais totais, baseando-se no exemplo das trocas de bens e do contrato de contraprestação de presentes realizado em algumas sociedades da Oceania e da América do Norte. Para o enfoque dessa reflexão seria interessante apreender algumas dessas ideias, pois elas auxiliam a desenvolver o argumento de que a socialização pode ser igualmente vista como um fenômeno social total. Procurar uma analogia entre o fenômeno das trocas dessas sociedades e a socialização como um fato social amplo e complexo, ou seja, analisar as práticas socializadoras nas suas dimensões econômica, moral, estética e política é uma forma de melhor compreendê-las e contextualizá-las nas realidades históricas.

Trata-se ainda de uma construção reflexiva que ajuda a circunscrever as instâncias de socialização numa perspectiva relacional, tendo como eixo central a participação do sujeito social em seu processo educativo. Mais do que isso, propõe pensar essas instâncias em sua dimensão econômica, moral, estética e política, dimensões responsáveis pela formação de um habitus, um sistema de disposições de cultura (MAUSS, op. cit.). Considera-se o processo de socialização das formações sociais como sendo um espaço plural de múltiplas dimensões. Ou seja, a socialização caracterizar-se-ia por oferecer uma ambiência em que o indivíduo encontra condições de forjar um sistema que mescle múltiplas referencias institucionais, um sistema de esquemas coerente, no entanto híbrido e fragmentado (Setton, 2009). Embora se saiba que no contexto social cada uma das instâncias formadoras desenvolva campos específicos de atuação, lógicas, valores éticos e morais distintos, compreende-se, a partir de Mauss, que são os próprios indivíduos que tecem as redes de sentido que os unificam em suas experiências de socialização. É o indivíduo que tem a capacidade de articular as múltiplas dimensões da vida ao longo de sua trajetória. É o sujeito a unidade social na qual se pode efetivar diferentes sentidos de ações, essas últimas derivadas das suas multíplices esferas de existência. Nele cruzam-se e interagem sentidos particulares e diferentes. Ele não é apenas o único portador efetivo de sentidos, mas a única sede possível de relações entre eles. ${ }^{5}$ 
Analisando o processo de socialização e considerando a articulação das ações educativas de várias instâncias produtoras de bens simbólicos, pretende-se compreender o jogo da reciprocidade e interação estabelecido pelos sujeitos. Em outras palavras, inspirando-se em Mauss, é possível apreender a dinâmica do campo da socialização, observando a tensão entre agentes e dimensões socializadores e, como consequência, a apreensão de uma luta simbólica de valores entre eles. Ao considerar a socialização contemporânea como um fato social total, a intenção não é apropriar-se da noção das trocas contratuais, potlach ou kula, de forma mecânica e linear. Ao contrário, o interesse é apropriar-se dessa noção nas análises acerca do tema, mobilização que ajuda a pensar a socialização como um fenômeno geral e generalizado, prática que implica necessariamente uma configuração social singular, uma reciprocidade, ainda que tensa e, às vezes, em forma de luta. Para Mauss (1974a)a realidade social constitui-se em um jogo competitivo e interessado. Um fenômeno que envolve a todos - indivíduos e instituições - e que, para se realizar, se manifesta nas dimensões econômica (origem social), política (posição ideológica), religiosa (crença) e estética (gosto) na vida de todos, entre outras. Como lembra Mauss (op. cit.), depois de um tanto forçadamente haver dividido e abstraído sobre algumas das matrizes de cultura, é preciso que os sociólogos se empenhem em recompor o todo.

Contudo, o fato total não chega a ser total pela simples reintegração dos aspectos descontínuos; é preciso ainda que o fato social total se encarne em uma experiência individual. Ou seja, primeiro em uma história individual que permita observar o comportamento dos seres totais e não divididos em faculdades; segundo, a partir de um sistema de interpretação que simultaneamente considere os múltiplos aspectos (físico, psíquico, sociológico) de todas as condutas. A interdisciplinaridade é a base pela qual sua perspectiva é tecida e seu argumento construído. Segundo Lévi-Strauss (1974, p. 14-15),

O fato social total apresenta-se, pois, com um caráter tridimensional. Deve fazer coincidir a dimensão propriamente sociológica com seus múltiplos aspectos sincrônicos: a dimensão histórica, ou diacrônica; e, finalmente, a dimensão fisiopsicológica. Ora, é só nos indivíduos que esta tríplice abordagem pode ser feita [...]. A noção de fato social total está em relação direta com a dupla preocupação, que para nós havia parecido única até agora, de ligar o social e o individual de um lado, o físico (ou o fisiológico) e o psíquico de outro.

Concordando com Martins (2008), essa visão corresponde a uma leitura que resgata a participação do sujeito na construção do social. Entender esse agente não mais como mero suporte mecânico, mas, sim, como capacidade expressiva, um sujeito que se perceba no outro e que os dois sejam seres igualmente atravessados pelo mesmo mundo. Nesse sentido, é uma forma de pensar a dimensão sistêmica sem perder de vista o vivido. A socialização encarada com base na noção de fato social 
total é concebida não como uma realidade bruta, mas um processo eficaz de reciprocidades de símbolos ou uma rede social de valores que se insere no mais profundo dos indivíduos, em suas disposições de cultura; desse modo, evidencia-se uma maneira mais dialética de conceber o social; não há uma escolha de protagonismo entre indivíduo e sociedade, pois ambos são duas totalidades articuladas em contextos histórico e socialmente bem definidos (MAUSS, 1974a, 1974b, 1974c).

A reciprocidade simbólica realizada no processo de socialização (de agentes entre si, entre agentes e instituições) permite revelar as práticas ou estratégias educativas concretas, ocultas e/ou difusas. A socialização como um fato social total não é uma realidade desencarnada, mas deriva de uma realidade constituída de experiências comuns que expressam a vida do grupo. Sua compreensão como um fato social total supera as dualidades conceituais presentes nas discussões tradicionais, articulando de modo dialógico categorias aparentemente opostas, como macro e micro, subjetivo e objetivo, individual e grupal, matéria e símbolo, pois, segundo esta perspectiva, tudo se mistura para compor o todo (CAILLÉ, 1998; MARTINS, 2008).

Em síntese, as contribuições de Mauss (1974a) podem ser matizadas na percepção de que a socialização é um fenômeno social total, pois permite dar ênfase ao aspecto simbólico das trocas como fundamento último das relações sociais entre pessoas morais, em suas múltiplas dimensões. Seu valor não está na troca simplesmente, mas no vínculo simbólico, reforçando a compreensão relacional dos distintos projetos das instâncias e agentes socializadores.

De fato, a socialização traduz um ato de pôr em prática um dom, no sentido maussiano do termo, ou seja, uma reciprocidade simbólica, a fim de garantir a vida individual e social; trata-se, então, de uma estratégia de manutenção de um projeto grupal e individual de difundir uma crença ou um ideal coletivo; dar, receber e retribuir simbolicamente projetos socializadores forjados no interior das instituições expressam ações contínuas de multiplicar crenças, estabelecer vínculos e compromissos sociais com base nos universos de símbolos específicos (MAUSS, op. cit.).

Como diria Caillé (1998), Mauss foi o responsável na França pela criação do campo sociológico do simbólico e sua ligação com a obrigação da reciprocidade. Afastando-se de uma rigidez conceitual, Mauss apresentaria uma compreensão ampla do conceito de simbólico, sem reduzi-lo ao linguístico ou pictórico, mas incorporando a ele todas as relações sociais. As trocas de bens, palavras e mulheres seriam apenas traduções individuais da presença do grupo e das necessidades diretas de cada um e de todos.

Os fatos sociais, diríamos, para resumir da melhor forma a especificidade da visão maussiana, tornam-se totais e não devem mais ser considerados como coisas, e sim como símbolos. Esse princípio não tem um alcance apenas metodológico, mas sócio-on- 
tológico. Não mais se dirá que se deve tratar os fatos sociais "como [se fossem] coisas", subentendendo "quando sabemos perfeitamente que não o são", e sim, que se deve tratar os fatos sociais como símbolos, porque sabemos perfeitamente que é essa, na verdade, a sua natureza. [...]; para Mauss, existe claramente uma obrigação de se submeter à lei do simbolismo, bem como à exigência de dar, receber e retribuir. Mesmo porque é tudo uma coisa só. Mas essa obrigação deixa de ser exercida com a exterioridade que, segundo Durkheim, é constitutiva do fato social, já que entre indivíduo e sociedade não há mais um hiato, mas uma relação de co-tradução. (C A ILLÉ, 1998, p. 15)

Posto isso, as contribuições de Mauss ajudam no entendimento sobre as relações de interdependência e sincronismo, entre: a) a constituição da sociedade, b) a constituição de uma cultura, com base na constituição e reciprocidade de conceitos e representações sociais e, por último, mas não em ordem de importância, c) a constituição do indivíduo; notadamente, três momentos simultâneos da construção da sociedade realizados pela socialização. A sociedade e o indivíduo só se realizam, portanto, quando indivíduos passam a objetivar e interiorizar um entendimento sobre as coisas sociais. A socialização como fenômeno social total é concebida, pois, como uma prática de garantir dialeticamente um corpo social, em sua materialidade e em seus símbolos, bem como a construção dos sujeitos sociais.

Trazendo a discussão para o universo conceitual da teoria da socialização, é possível afirmar que é no âmbito das configurações interpessoais e primárias que a dádiva (troca simbólica) proporcionada pelo processo de socialização aparece com maior nitidez. É nelas que se veem nascer as redes de sentido, sistemas de trocas diretas entre familiares, vizinhos e amigos; no entanto, as reciprocidades também se dão nos níveis institucional e grupal e mesmo virtual. No desenvolvimento de uma sociologia das reciprocidades simbólicas é preciso prestar atenção ao modo de organização das socializações primárias, ${ }^{6}$ isto é, à esfera microssociológica, com a intenção de verificar as perspectivas de construção de um tipo de reciprocidade mais ampla e geral.

\section{O conceito de (con)figuração e o fenômeno da socialização}

O conceito de figuração distingue-se de muitos outros conceitos teóricos da sociologia por incluir expressamente os seres humanos em sua formação [...]. O modo de sua vida conjunta em grupos grandes e pequenos é, de certa maneira, singular e sempre co-determinado pela transmissão de conhecimento de uma geração a outra, portanto por meio do ingresso do singular no mundo simbólico específico de uma figuração já existente de seres humanos. (ELIAS, 2006, p. 25)

Segundo Elias, só podemos compreender muitos dos aspectos do comportamento ou das ações individuais se começarmos pelo estudo do tipo da sua interdependência, pelo estudo da estrutura das suas sociedades, em resumo, das (con)figurações 
que formam uns com os outros. Para ele, torna-se necessário não só explorar uma unidade compósita (indivíduo) em termos das suas partes componentes (sua rede de reciprocidade simbólica e material), como também explorar a maneira com esses componentes individuais se ligam uns aos outros, de modo a formarem uma unidade em rede. Para os interesses desta discussão, parte-se da hipótese de que o aporte teórico eliasiano é um grande auxiliar para se compreender, identificar e analisar os processos socializadores, que nada mais são do que as relações entre singularidades individuais com o entorno e/ou a ambiência objetiva e subjetiva que as envolvem. Nada mais são do que as conexões de sentido de indivíduos entre si, num enredo contínuo, intenso e tenso de uma multiplicidade de dimensões e diferenças sociais. Para Elias (1990), a tensão é constitutiva das relações sociais, é natural das conexões humanas.

As configurações, segundo Elias, têm de ser interpretadas como representações de seres humanos ligados uns aos outros no tempo e no espaço. A sequência de movimentos entre os seres só pode ser compreendida e explicada em termos da dinâmica imanente de sua interdependência simbólica. A dependência funcional dos movimentos em ambos os lados não é menor neste caso do que no caso do conflito ou de uma cooperação. O exemplo de uma estrutura reticular articulada mostra como a teia de relações humanas muda, quando muda a distribuição de força entre seus componentes. Para Elias, o crescimento de um indivíduo em (con) figurações humanas, como processo e experiência, é condição indispensável do desenvolvimento rumo à humanidade. Dessa forma, socialização e individualização de um ser humano são noções diferentes para expressar o mesmo processo. Cada ser humano assemelha-se aos outros e é, ao mesmo tempo, diferente de todos os outros (ELIAS, 2006).

Para o autor, a sociologia deveria se ocupar de entender não só as singularidades individuais, mas, sobretudo, identificar e analisar as relações que essas unidades individualizadas estabelecem entre si em um contexto social total e multidimensional. Propôs pensar a tarefa da sociologia como aquela que se esforça em compreender as configurações humanas, as relações indissociáveis entre indivíduo e as redes de relacionamento que ele estabelece em suas conexões sociais. Expressões como integração, interdependência, trama, enredo e tecido social são significativas para desenhar uma compreensão complexa e multideterminada das articulações humanas e da constituição da realidade social como um fato social total.

Esta nova forma de olhar introduz necessariamente uma crítica e uma ruptura com antigos vocabulários; antigos paradigmas que visualizam indivíduos isolados, estruturas institucionais fixas e estáveis; apresenta a força dos enredos coletivos, o equilíbrio de forças entre indivíduos que disputam a sobrevivência social; provoca novos entendimentos sobre o poder de personalidades ou celebridades conduzirem a história; relativiza noções como poder e função com o intuito de explicitar as 
conexões de sentido do jogo social. Metaforicamente, faz uso da noção de jogo para expressar um entendimento de que as relações sociais, as ações e práticas culturais comportamentais são produto de trocas simbólicas realizadas nos processos socializadores, relações estas que podem ser de disputa ou de parceria. No jogo social, lembra Elias (1999, 1994), pode-se visualizar parceiros, inimigos ou adversários.

Segundo esta perspectiva, as estruturas sociais, ou seja, as redes de conexão são históricas e possuem regularidades e leis gerais específicas. Essas não são fixas, nem estáveis; respondem a um equilíbrio de forças entre os sujeitos/fios que as compõem. As regras de cada configuração social são construídas com base nos instintos (fome-sexo), necessidades (segurança-terras) e valores (poder, status, conhecimento) de cada um de seus componentes e, portanto, respondem a circunstâncias específicas de socialização. Os impulsos dos instintos - agressividade, sexualidade e ou segurança - são moldados pelos constrangimentos societários; a cada sociedade essas pulsões são diferentemente moldadas e controladas, fazendo com que ao longo da história tenhamos uma diversidade grande de comportamentos multideterminados. O autor lança mão, portanto, do conceito reticular - uma estrutura tecida na forma de rede - que expressa a condição relacional de seus componentes. Segundo Elias, convencionalmente entende-se expressões como razão, consciente, instinto, alma, espírito sendo imutáveis e inatas a todos nós. Contudo, para ele é um equivoco substantivar, fixar em um único sentido essas expressões, sendo que elas são fenômenos relacionais, históricos e socialmente construídos pelas trocas simbólicas. Elas emergem de um fato social total de interações que se mantém desde o nascer. São formas particulares de autorregulação, de pessoa em relação/função a outras pessoas e coisas (ELIAS, 1994).

De acordo com essa perspectiva, tudo estaria condicionado à estrutura e a constelação histórica das sociedades. Nesse sentido, sua preocupação maior é romper com a falsa discussão: o que seria mais importante na condução da história: os indivíduos ou a sociedade? É possível identificar em Elias (op. cit.) passagens em que retoma essa discussão, amarrando os limites estruturais e individuais na condução da história. Para ele, o feixe de condicionamentos sociais multideterminados e as complexas configurações humanas em fatos sociais totais é que são responsáveis pela trama da construção dos processos sociais. Um salto epistemológico perpassa esta afirmação ao considerar que toda sociedade é sempre muito firme e muito elástica; isto é, sempre dá espaço para a força individual, mas esta sempre condicionada pela rede de relações e equilíbrio de forças entre os parceiros. Tal como Mauss, compreende as relações de interdependência e simultaneidade entre: a) a constituição da sociedade, b) a constituição de uma cultura, com base na constituição e reciprocidade de conceitos e representações sociais e c) a constituição do indivíduo. Três momentos simultâneos da construção da sociedade realizados pela socialização e individualização. 
As configurações humanas têm uma ordem e estão sujeitas a leis diferentes e mais poderosas do que aquilo que planejam e querem os próprios indivíduos que as compõem. Para Elias, é a maior liberdade das relações humanas, no tocante ao controle exercido por mecanismos automáticos hereditários, que realmente abre caminho para a livre atuação dos mecanismos da rede social; são as regularidades ou leis nascidas do entrelaçamento e da interdependência dos indivíduos que possuem plena força; a socialização e o entrelaçamento humano resultam em leis e estruturas de tipo especial. Contudo, não são leis desejáveis ou planejáveis. Justamente por isso, o irrevogável entrelaçamento dos atos, necessidades, ideias e impulsos de muitas pessoas dá origem a estruturas e transformações estruturais numa ordem e direção específicas que não são simplesmente animais, naturais ou espirituais, racionais ou tampouco irracionais, mas simplesmente fenômenos sociais totais (ELIAS, 1994, 1999).

\section{Algumas similaridades}

Para os interesses dessa reflexão, é possível afirmar que Mauss e Elias, com base nos conceitos de fato social total e (con)figuração, permitem visualizar a noção de socialização ou as relações individuo e sociedade, com base em uma perspectiva dialógica, multidimensional e interdisciplinar. Explicitando a ideia de continuidade e processo na construção do social, a socialização e/ou as relações indivíduo e sociedade constituem-se em algo que possui história, são devedoras de uma compreensão biológica e psicológica dos fenômenos produtores de sentido. Estar em sociedade é sempre e simultaneamente estar inscrito em uma constelação de sentidos; não se tratando apenas de uma integração estrutural, mas sim de uma integração cultural, necessária e simultaneamente objetiva e subjetiva (MAUSS, 1974a, 1974b, 1974c; ELIAS, 1994).

As formulações dos autores salientam os processos socializadores como um campo de investigação que mistura fundamental e concomitantemente estruturas, atores, sentido e história. Concordando com Berthelot (1988), compreende-se que é na articulação dessa complexidade de dimensões que se poderia construir uma nova linha de abordagem dos processos socializadores. De acordo com tal perspectiva, as trocas estão inscritas numa configuração social total, e os conceitos complementares de socialização nesse paradigma são a historicidade e a subjetividade. Tratando de seres de relações, o social é a reinvenção e integração de subjetividades.

É forçoso afirmar que a leitura dos processos sociais, a partir do eixo dos conceitos de fato social total e (con)figuração, revela relações indissociáveis entre indivíduo e sociedade. Mais do que isso, fortalece-se a hipótese de que as reflexões de ambos, ainda que não nomeadas dessa forma, podem servir de base na construção do 
paradigma metodológico e conceitual dos processos socializadores na contemporaneidade como sendo totais e devedores de uma rede de sentidos multidimensionais. Ademais, as contribuições de Mauss e Elias podem trazer novas luzes para um debate improdutivo entre leituras que apelam e/ou enfatizam apenas uma das bases responsáveis pela estruturação do social e do individual. Nem tanto a sociedade, nem tanto o indivíduo. A sociedade não existe, unicamente, em função dos indivíduos; tampouco os indivíduos existem, exclusivamente, em função da sociedade. Ambos necessitam igualmente um do outro e vivem, simultânea e inexoravelmente, em função do outro, em relações recíprocas e funcionais totais (multidimensionais) (MAUSS, 1974a; ELIAS, 1990).

Tem-se a impressão de que Mauss e Elias vão além de uma análise simbólica dos processos de formação dos indivíduos, ao acrescentarem as singularidades dos indivíduos e suas relações com a ambiência que os envolve. O estudo da morfologia ou das estruturas (MAUSS, 1974a; 1974c) ou das configurações (ELIAS, 2006; 1999) históricas, sociais e psicológicas são a base das investigações de ambos. Mauss e Elias chamam a atenção para a ideia de continuidade, contiguidade implícita entre singularidades sociais, a individualidade de cada um dos indivíduos e as estruturas materiais e simbólicas (configurações) que os envolvem. Devem ser considerados como autores de base, pois nos auxiliam na formação da compreensão sociológica; além disso, oferecem uma perspectiva analítica ampliada, pertinente aos estudos em sociedades complexas, mundializadas e plurideterminadas como as sociedades contemporâneas.

Nesse sentido, a singularidade do ponto de vista analítico de ambos envolve uma postura intelectual sobre o fato observado concreto, que impõe um esforço conceitual diferenciado. O raciocínio sociológico de ambos permite observar que é preciso duvidar de alguns pares de conceitos muito difundidos em nossa área. Entre eles: indivíduo e sociedade, micro-macro, objetivo e subjetivo etc., pares dicotômicos que não explicitam as redes de conexão de sentidos, a troca simbólica em constante construção, devedora de configurações sociais determinadas. Posto isso, justifica-se o argumento que procura centrar-se num duplo desafio de explorar a perspectiva teórico-metodológica e o corpo conceitual de ambos na tentativa de aprofundar as análises acerca dos processos educativos-socializadores, enquanto configurações ou fenômenos históricos, dialéticos, complexos, totais, multideterminados, responsáveis tanto pela construção de individualidades como pela própria sociedade.

Para ambos, a realidade se processaria a partir da articulação de múltiplas dimensões da vida social - econômicas, políticas, culturais, religiosas, estéticas (entre outras) - e a tarefa do observador social seria compreender as redes de sentido, conflitos ou afinidades construídas pelos grupos nessa complexidade (MAUSS, 1974a; ELIAS, 1994). As trocas simbólicas nada mais seriam do que estratégias de 
construção/manutenção das interdependências sociais, estratégias de vínculos políticos, econômicos, religiosos, estéticos, entre outros; trocas e enredos sociais que ora explicitariam relações de força, prestígio e/ou autoridade, ora expressariam parcerias interessadas em um jogo coletivo e individual.

Um novo paradigma, interdisciplinar e multidimensional entre as partes constitutivas do social em processo, se insurge numa explicitação convincente, com base em princípios epistemológicos convergentes. Nesse sentido, pares de conceitos como sociedade e indivíduo, micro e macro, ou mesmos noções fortemente marcada pelo ponto de vista da rigidez, como socialização ou individualização, entre outros, deveriam ser submetidos a essa nova postura metodológica, mais relacional e dialética, a fim de serem instrumentos eficazes de interpretação do social.

Ao projetar a figura do indivíduo enredado em uma teia de relações sociais - (con)figurações - ou em fatos sociais totais, Elias e Mauss protestam contra o entendimento de que as instituições são entidades acima e além de nós. Eles provocam uma mudança de percepção e convidam para uma alteração de perspectiva sobre as interações sociais. Segundo os autores, só se pode compreender muitos aspectos do comportamento ou das ações das pessoas se começarmos pelo estudo do tipo de suas relações simbólicas e materiais como fatos sociais totais, pelo estudo das diferentes dimensões estruturais - psíquica, fisiológica e morfológica - da sociedade; em outras palavras, só se pode compreender muitos aspectos do comportamento ou das ações individuais com o estudo das configurações/figurações que formam uns com os outros. Portanto, em síntese, o que é moldado pela sociedade também molda; é a autorregulação do indivíduo em relação aos outros que estabelece limites à autorregulação destes. Dito de outra forma, o indivíduo é ao mesmo tempo moeda e matriz na configuração dos fatos sociais totais (MAUSS, 1974a; ELIAS, 1994).

\section{Notas}

1. No campo da Educação é possível destacar alguns autores que vêm trabalhando com Norbert Elias, embora distante das questões relativas aos processos socializadores (BRAND ÃO, 2003, LEÃO, 2007; BRAGA, 2010; HUNGER et al., 2011; VEIGA, 2011).

2. Um esforço de aproximação entre Mauss e Elias pode ser encontrado também em Pontes (1999).

3. Os conceitos de figuração e configuração são intercambiáveis e sinônimos. São igualmente usados por Elias na maioria de seus escritos, embora em suas últimas publicações tenha dado preferência para o primeiro deles, sendo objeto de um verbete em dicionário (ELIAS, 2006).

4. $\quad$ Essa obra de Mauss foi publicada em 1924 e os primeiros escritos de Elias datam de 1936.

5. As noções de indivíduo, sujeito e agente social são usadas como sinônimos, ainda que se tenha consciência das distinções teóricas dadas pela sociologia e pela filosofia.

6. No sentido de Berger e Luckmann (1983). 


\section{Referências}

ANSART, P. Les sociologies contemporaines. Paris: Seuil, 1990.

BERGER, P.; LUCKMANN, T. A construção social da realidade. Petrópolis: Vozes, 1983.

BERTHELOT, J.M. Pour un bilan de la sociologie de l'éducation. Toulouse: Université de Toulouse-Le Mirail, 1983.

BERTHELOT, J.M. Reflexion sur la pertinence du concept de socialisation. In: TABLE RONDE DE LYON, 1988, Lyon. Actes... Lyon: Université Lumière - Lyon 2, 1988.

BRAGA, E.; ABREU, E. Uma reflexão acerca da noção de identidade sob o ponto de vista de Elias e Bourdieu. In: BASTOS, L.; LOPES, L. Estudos de identidade: entre saberes e práticas. Rio de Janeiro: Garamond, 2010.

BRANDÃO, C.F. Norbert Elias: formação, educação e emoções no processo de civilização. Petrópolis, Vozes, 2003.

CAHIER internationaux de sociologie, Paris, v. 99, n. 2, 1995.

CAILLÉ, A. Nem holismo, nem individualismo metodológicos: Marcel Mauss e o paradigma da dádiva. Revista Brasileira de Ciências Sociais, São Paulo, v. 13, n. 8, p. 5-38, 1998.

CORCUFF, P. As novas sociologias: construções da realidade social. Bauru: Edusc, 2001.

DARMON, M. La socialisation. Paris: Colin, 2006.

ELIAS, N. O processo civilizador: uma história dos costumes. Rio de Janeiro: Zahar, 1990. v. 1.

ELIAS, N. A sociedade dos indivíduos. Rio de Janeiro: Zahar, 1994.

ELIAS, N. Introdução à sociologia. Lisboa: Edições 70, 1999.

ELIAS, N. Norbert Elias por ele mesmo. Rio de Janeiro: Zahar, 2001.

ELIAS, N. Conceitos sociológicos fundamentais. In: ELIAS, N. Escritos e ensaios 1. Rio de Janeiro: Zahar, 2006. p. 27.

FOURNIER, M. Marcel Mauss. Paris: Fayard, 1994.

HEINICH, N. A sociologia de Norbert Elias. Lisboa: Atividades Editoriais, 2001.

HUNGER, D.; ROSSI, F.; SOUZA NETO, S. A teoria de Norbert Elias: uma análise do ser professor. Educação \& Pesquisa, São Paulo, v. 37, n. 4, p. 697-710, dez. 2011. 
LANNA, M. Notas sobre Marcel Mauss e o ensaio sobre a dádiva. Revista de Sociologia e Política, Curitiba, n. 14, p. 173-194, jun. 2000.

LEÃO, A.B. Norbert Elias e a educação. Belo Horizonte: Autêntica, 2007.

LEDEL, D. Norbert Elias: vie, oeuvre, concepts. Paris: Ellipses, 2009.

LÈVI-STRAUSS, C. Introdução: a obra de Marcel Mauss. In: Sociologia e Antropologia. São Paulo: EPU/Edusp, 1974. v. 2, p. 1-37.

MARTINS, P.H. De Lévi-Strauss a Mauss: movimento antiutilitarista nas ciências sociais - itinerários do dom. Revista Brasileira de Ciências Sociais, São Paulo, v. 23, n. 66, p. 105-130, fev. 2008.

MAUSS, M. Ensaio sobre a dádiva: forma e razão da troca nas sociedades arcaicas. In: Sociologia e Antropologia. São Paulo: EPU/Edusp, 1974a. v. 2.

MAUSS, M. As técnicas corporais. In: Sociologia e Antropologia. São Paulo: EPU/ Edusp, 1974b. v. 2.

MAUSS, M. Morfologia social. In: Sociologia e Antropologia. São Paulo: EPU/Edusp, 1974c. v. 2.

OLIVEIRA, R.C. Introdução a uma leitura de Mauss. In: OLIVEIRA, R.C. (Org.). Marcel Mauss. São Paulo: Ática, 1979. p. 7-50.

PONTES, H. Elias, renovador da ciência social. In: WAIZBORT, L. (Org.). Dossiê Norbert Elias. São Paulo: Edusp, 1999.

SETTON, M.G.J. Socialização e cultura - ensaios teóricos. São Paulo: AnnaBlume, 2012.

VEIGA, C.G. Cuestiones teóricas y conceptuales para la investigación de la psicogênesis y socio génesis de los procesos escolarizadores. Universitas Humanistica, Bogotá, v. 71, p. 85-100, 2011.

Recebido em 28 de abril de 2012.

Aprovado em 26 de outubro de 2012. 